\title{
Gene expression in the brain and kidney of rainbow trout in response to handling stress Aleksei Krasnov*1, Heikki Koskinen ${ }^{\dagger 1}$, Petri Pehkonen ${ }^{\dagger 1}$, Caird E Rexroad III ${ }^{2}$, Sergey Afanasyev ${ }^{3}$ and Hannu Mölsä ${ }^{1}$
}

\begin{abstract}
Address: ${ }^{1}$ Institute of Applied Biotechnology, University of Kuopio, P.O.B. 1627, 70211 Kuopio, Finland, ${ }^{2}$ National Center for Cool and Cold Water Aquaculture, USDA-ARS, 11876 Leetown Road, Kearneysville, WV 25430, USA and ${ }^{3}$ Sechenov Institute of Evolutionary Physiology and Biochemistry, M.Toreza av. 44, Petersburg, 194223, Russia

Email: Aleksei Krasnov* - krasnov@uku.fi; Heikki Koskinen - heikki.koskinen@uku.fi; Petri Pehkonen - petri.pehkonen@uku.fi; Caird E Rexroad - CRexroad@ncccwa.ars.usda.gov; Sergey Afanasyev - afan@iephb.ru; Hannu Mölsä - Hannu.Molsa@uku.fi

* Corresponding author †Equal contributors
\end{abstract}

Published: 06 January 2005

BMC Genomics 2005, 6:3 doi:10.1186/147|-2164-6-3
Received: 06 August 2004

Accepted: 06 January 2005

This article is available from: http://www.biomedcentral.com/147I-2/64/6/3

(C) 2005 Krasnov et al; licensee BioMed Central Ltd.

This is an Open Access article distributed under the terms of the Creative Commons Attribution License (http://creativecommons.org/licenses/by/2.0), which permits unrestricted use, distribution, and reproduction in any medium, provided the original work is properly cited.

\begin{abstract}
Background: Microarray technologies are rapidly becoming available for new species including teleost fishes. We constructed a rainbow trout cDNA microarray targeted at the identification of genes which are differentially expressed in response to environmental stressors. This platform included clones from normalized and subtracted libraries and genes selected through functional annotation. Present study focused on time-course comparisons of stress responses in the brain and kidney and the identification of a set of genes which are diagnostic for stress response.

Results: Fish were stressed with handling and samples were collected I, 3 and 5 days after the first exposure. Gene expression profiles were analysed in terms of Gene Ontology categories. Stress affected different functional groups of genes in the tissues studied. Mitochondria, extracellular matrix and endopeptidases (especially collagenases) were the major targets in kidney. Stress response in brain was characterized with dramatic temporal alterations. Metal ion binding proteins, glycolytic enzymes and motor proteins were induced transiently, whereas expression of genes involved in stress and immune response, cell proliferation and growth, signal transduction and apoptosis, protein biosynthesis and folding changed in a reciprocal fashion. Despite dramatic difference between tissues and time-points, we were able to identify a group of $\mathbf{4 8}$ genes that showed strong correlation of expression profiles (Pearson $r>|0.65|$ ) in 35 microarray experiments being regulated by stress. We evaluated performance of the clone sets used for preparation of microarray. Overall, the number of differentially expressed genes was markedly higher in EST than in genes selected through Gene Ontology annotations, however $63 \%$ of stress-responsive genes were from this group.
\end{abstract}

Conclusions: I. Stress responses in fish brain and kidney are different in function and time-course. 2. Identification of stress-regulated genes provides the possibility for measuring stress responses in various conditions and further search for the functionally related genes. 


\section{Background}

Until recently multiple gene expression profiling was applied almost exclusively to human and a few model organisms. At present cDNA microarrays are being constructed for new species including teleost fishes [1-6]. Since EST sequencing projects are carried out with a large number of species, continuous development of new platforms can be expected in the future. We designed a salmonid fish cDNA microarray primarily to characterize responses to stress, toxicity and pathogens. This paper focuses on time-course comparisons of stress responses in rainbow trout and the usage of functional annotation to conduct analyses of gene expression data.

Functional annotation of genes, especially Gene Ontology [7] is increasingly being used for analyses and interpretation of microarray results [8-13]. We applied Gene Ontology in several modes to facilitate implementation of our research tasks. Furthermore, experimental results generated guidelines for the development of specialized microarrays. Well designed platforms are expected to ensure identification of differentially expressed genes while containing representative coverage from important functional groups. Custom made microarrays include clones from cDNA libraries and/or selected genes, which have advantages and drawbacks. Indiscriminant spotting of EST may result in under representation of many functional classes. On the other hand selection of genes fully relies on annotations and hypotheses, which can be misleading and limit possibilities for nontrivial findings. We used clones from normalized and subtracted cDNA libraries as well as genes selected by the functional categories of Gene Ontology for inclusion onto a microarray targeted at characterizing transcriptome responses to environmental stressors.
Designing a new platform requires balancing a large number of genes versus multiple replications of spots, which enhances statistical analyses of data. The rainbow trout microarray was prepared by spotting of relatively small number of genes (1300) in 6 replicates. We show that multiple replications combined with the dye-swap design of hybridization $[14,15]$ allows for accurate detection of relatively small alterations in expression levels, which is important for the functional interpretation of results.

Stress is closely associated with many diverse issues in fish biology and environmental research (reviewed in [16]). Stress is generally defined as the reaction to external forces and abnormal conditions that tend to disturb an organism's homeostasis. To illustrate the major trends in the studies of stress in fish, we performed a computer-assisted analysis of Medline abstracts covering this area (Table 1). Salmonids have been studied more extensively than any other fish species. Research has focused on various biotic and abiotic factors including toxicity, environmental parameters (oxygen, temperature, salinity, acidosis), diseases, social interactions (crowding, aggressiveness) and farming manipulations. Analysis of Medline abstracts indicated physiological processes, cellular structure and selected proteins that have been the major foci of previous fish stress studies. This provided an outline for interpretation of our results. We analyzed the effects of stress on the transcriptome in the brain and kidney, which are considered important target tissues along with muscle, blood cells, liver and epithelia. We report a profound difference of stress response in these tissues and the identification of a diagnostic set of genes.

Table I: Thematic associations in studies of fish stress. Computer-assisted analysis of I I 29 Medline abstracts was performed as described in Methods. Terms that were over-represented in the abstracts (exact Fisher's test, $P<0.05$ ) are ranked by the numbers of occurrence.

\begin{tabular}{|c|c|}
\hline Category & Terms (counts/ 1000 abstracts) \\
\hline Species & Salmonids (126.4), carp (68.9), eels (67.0), catfish (37.7), tilapia (38.7) \\
\hline Stressors & $\begin{array}{l}\text { Toxicity (440.6), temperature (178.3), oxygen (9I.5), confinement (52.8), salinity }(46.2) \text {, hypoxia (54.7), diseases (20.8), } \\
\text { crowding (23.6), acidosis ( } 17.9) \text {, aggressiveness ( } 11.3)\end{array}$ \\
\hline Messengers & Cortisol (208.5), catecholamines (159.4), steroids (92.5) \\
\hline Tissues & $\begin{array}{l}\text { Muscle (197.2), blood cells (152.9), pituitary (I 19.8), liver (123.6), epithelia (96.2), brain (90.6), kidney (89.6), heart (5I.9), } \\
\text { skin (42.5) }\end{array}$ \\
\hline Cellular structures & $\begin{array}{l}\text { Cytosol (42.5), collagen (17.0), cytoskeleton (15.I), microsome (15.I), microtubule (14.2), lysosomes (13.2), peroxisome } \\
\text { (4.7) }\end{array}$ \\
\hline Oxidative stress & $\begin{array}{l}\text { Glutathion (167.9), oxidant (93.4), antioxidant (90.6), peroxide (66.0), radical (55.7), superoxide (40.6), catalase (35.8), } \\
\text { redox (18.9) }\end{array}$ \\
\hline Other processes & $\begin{array}{l}\text { Immunity }(9 \mid .5) \text {, secretion }(80.2) \text {, metabolism }(74) \text {, transport }(56.6) \text {, defense }(52.8) \text {, necrosis }(28.3) \text {, apoptosis }(\mid 8.9) \text {, } \\
\text { phosphorylation }(|15 .|) \text {, proteolysis }(7.5)\end{array}$ \\
\hline Metabolites & $\begin{array}{l}\text { Ion (987.7), iron (2I5.I), glucose (14|.5), lactate (67.9), lipid (74.5), zinc (5I.9), phospholipid (II.3), triglyceride (II.3), } \\
\text { lipopolysaccharide (9.4) }\end{array}$ \\
\hline Proteins & $\begin{array}{l}\text { Enzymes }(180.2) \text {, heat-shock proteins }(84.0) \text {, hemoglobin }(37.7) \text {, metallothionein }(37.7) \text {, transferase }(32.1) \text {, phosphatase } \\
(26.4) \text {, chaperones }(21.7) \text {, glutathion-S-transferase }(17.0) \text {, transaminase }(17.0), \mathrm{Na} / \mathrm{K}-\mathrm{ATPase}(17.0) \text {, aminotransferase }(8.5) \text {, } \\
\text { mitogen-activated kinases }(4.7)\end{array}$ \\
\hline
\end{tabular}



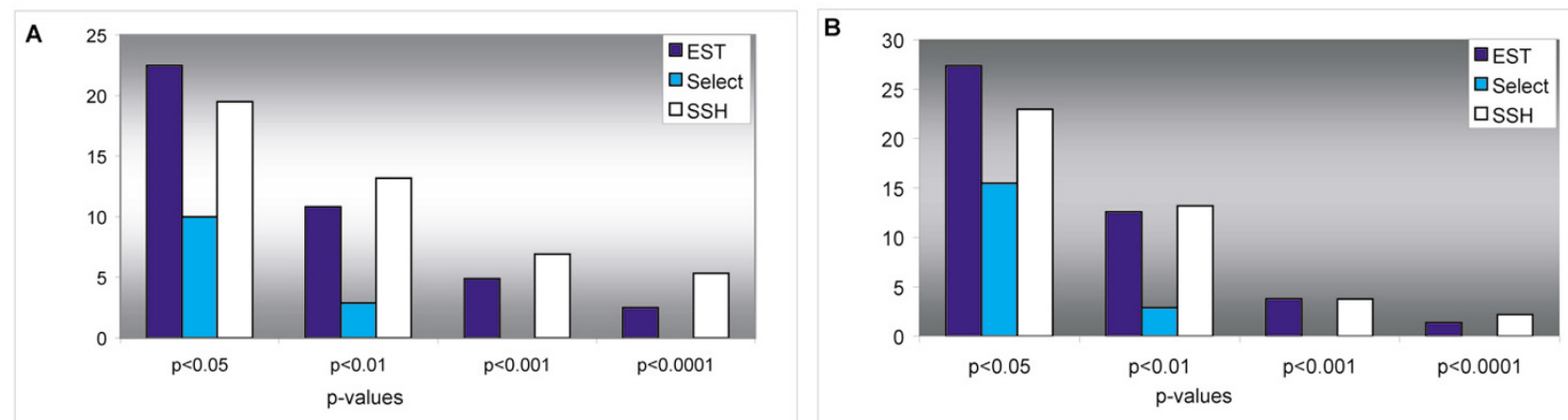

\section{Figure I}

Performance of the clone sets used for preparation of the microarray. Figure shows frequencies of genes that were differentially expressed in at least 5 samples at different p-values (Student's t-test). A: this study (stress response), B: related experiments (exposure to aquatic contaminants [34], response to stress, cortisol and combination of these treatments, challenge with bacterial antigens, M74 disease). SSH - subtracted cDNA libraries, EST - normalized libraries, Select - genes chosen by the Gene Ontology functional categories.

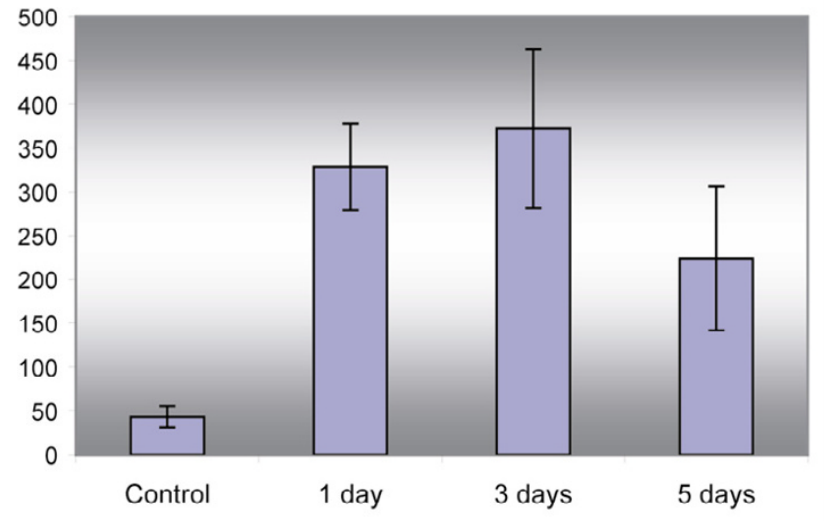

Figure 2

Plasma cortisol levels. The data are mean \pm SE $(n=4)$. Difference between the control and stressed fish is significant (Student's t-test, $\mathrm{p}<0.05$ ).

\section{Results}

\section{Design of cDNA microarray}

The rainbow trout cDNA microarray was composed of EST and selected genes. The cDNA libraries were prepared from tissues of stressed fish using suppression subtractive hybridization, SSH [17] and a modification of the capfinder method [18] supplemented with enzymatic normalization [19]. We sequenced 2000 clones and redundancy of the subtracted libraries was markedly greater than that of the normalized $(306 \%$ and $134 \%$ respec- tively). In addition to EST we selected rainbow trout transcripts from the normalized multi-tissue cDNA library [20] based on their assignment to functional categories of Gene Ontology (stress and defense response, regulation of cell cycle, signal transduction, chaperone activity and apoptosis). The selected genes substantially improved the coverage of many functional classes (Table 2), though the number of differentially expressed genes in this group was markedly inferior to EST (Figure 1). Subtraction cloning enriched genes that showed strong alteration of expression at response to stress ( $\mathrm{p}<0.01$ or lower, Figure $1 \mathrm{~A}$ ), however the SSH clone set did not provide any advantage when microarray was used for the related research tasks (Figure 1B).

2 Stress response in the brain and kidney of rainbow trout 2.I Differentially expressed genes

Fish were stressed with netting and samples were collected 1,3 and 5 days after the first exposure. We used plasma cortisol as a stress marker [21]. The hormone levels increased 7.6-fold after 1 day and did not change significantly to the end of experiment (Figure 2).

Microarray results were submitted to GEO (GSM22355). Two genes were up-regulated in both tissues at all timepoints (Figure 3). One is a putative homolog to the mammalian $\mathrm{N}$-myc regulated genes, which are induced with steroid hormones in the brain [22] and kidney [23]. Mitochondrial ADP, ATP carrier can be implicated to both normal functions and cell death [24]. Metallothionein-IL, a classical stress marker was induced to the end of experiment and a similar profile was seen in midkine precursor 
Table 2: Presentation of the Gene Ontology functional categories in the microarray. Table shows the numbers and frequncies of genes in the clone sets that were used for spotting (SSH - subtracted libraries, EST - normalized libraries).

\begin{tabular}{lcccc}
\hline Gene Ontology classes & N on slide & SSH & EST & Selected \\
\hline Response to external stimulus & 147 & $1 \mathrm{I}(0.07)$ & $48(0.1 \mathrm{I})$ & $88(0.31)$ \\
Response to stress & 145 & $7(0.04)$ & $30(0.07)$ & $108(0.38)$ \\
Defense response & 105 & $6(0.04)$ & $34(0.08)$ & $65(0.23)$ \\
Humoral immune response & 42 & $3(0.02)$ & $13(0.03)$ & $26(0.09)$ \\
Apoptosis & 79 & $6(0.04)$ & $10(0.02)$ & $63(0.22)$ \\
Cell communication & 139 & $11(0.07)$ & $45(0.11)$ & $83(0.29)$ \\
Cell proliferation & 82 & $8(0.05)$ & $23(0.05)$ & $51(0.18)$ \\
Cell cycle & 62 & $2(0.01)$ & $17(0.04)$ & $43(0.15)$ \\
Signal transduction & 114 & $5(0.03)$ & $32(0.07)$ & $77(0.27)$ \\
Receptor activity & 49 & $3(0.02)$ & $18(0.04)$ & $28(0.10)$ \\
Intracellular signaling cascade & 49 & $3(0.02)$ & $15(0.04)$ & $15(0.04)$ \\
DNA metabolism & 47 & $5(0.03)$ & $21(0.05)$ & $27(0.11)$ \\
Transcription & 67 & $9(0.05)$ & $12(0.03)$ & $37(0.13)$ \\
Chaperone activity & 41 & $4(0.02)$ & $25(0.09)$
\end{tabular}

(growth factor), histone H1.0 and B-cell translocation protein 1. In kidney we observed consistent up-regulation of genes related to energy metabolism, such as mitochondrial proteins (cytochromes $\mathrm{b}$ and $\mathrm{c}$, cytochrome oxidases), enzymes (glyceraldehyde 3-phosphate dehydrogenase, fructose-bisphosphate aldolase, serinepyruvate aminotransferase) and similar profiles were seen in two heat shock proteins and two signal transducers (cytohesin binding protein and GRB2-adaptor). The repressed genes were related to actin binding (coronin and profilin) and immune response (meprin, immunoglobulin epsilon receptor, thymosin and lysozyme).

Rapid alteration of gene expression was a remarkable feature of stress response in the brain. Only one gene, aquaporin, was up-regulated for the duration of the experiment. Water channel aquaporin plays a key role in water homeostasis being implicated in various physiological processes and pathological conditions [25]. A panel of genes which showed markedly increased expression after 1 day was also suppressed after 5 days. Surprisingly, this group included mainly genes that are predominantly expressed in skeletal or cardiac muscle (myosin light chain 1 and 2, skeletal and cardiac isoforms, myosin heavy chain, troponin I, T and $\mathrm{C}$ ) or are involved in regulation of muscle contraction (parvalbumin alpha and sarcoplasmic reticulum calcium ATPase). An opposite tendency was shown by a large group of genes however the magnitude of expression changes was smaller. We analysed 5 differentially expressed genes with qPCR and the results were in close concordance with the microarray data (not shown).

\subsection{Functional classes}

The search for enriched Gene Ontology functional categories in the lists of differentially expressed genes found almost no overlap between the tissues (Table 3). In the brain stress affected binding and transport of metal ions, especially calcium and manganese, chaperones and heat shock proteins, cytoskeleton and microtubules and a number of signaling pathways; whereas, mitochondrion, extracellular structures and peptidases appeared the primary targets in the kidney.

Comparison of the differentially expressed genes by the Gene Ontology categories suggested coordinated regulation of various cellular functions in the brain. Early stress response was marked with transient induction of the cytoskeleton proteins and similar profiles were observed in the metal binding proteins and enzymes of carbohydrate metabolism (Figure 4). An opposite expression pattern was shown by a large group of genes involved in stress and immune response, regulation of growth and cell cycle, apoptosis, signal transduction and cell to cell signaling. This was in parallel with enhancement of transcription and translation, ubiquitin-dependent protein catabolism and protein folding. In the kidney the temporal alterations were much weaker. Expression of metal binding proteins increased slowly in parallel with peptidases. Strong induction of collagenases coincided with decrease of collagen expression. At the same time a number of metabolic functions were suppressed (oxidative phosphorylation and oxidoreductase activity, amine metabolism and RNA binding).

\section{Stress-responsive genes}

Microarray design included genes from functional categories which were expected to be affected by stress (Table 2). Overall observations of differences in gene expression from this group in response to handling stress were minimal; however, this could be accounted for by its heterogeneity. Therefore we searched for the subgroups of genes 
Both tissues

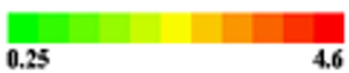

$N$-myc regulated gene 1

ADP,ATP carrier

Metallothionein'IL

Midkine precursor

Histone H1.0

B-cell translocation protein 1

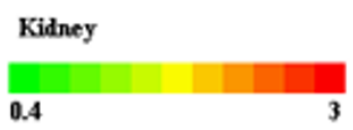

Cytochrome b

Cytochrome c.

Cytochtome c oxidase subunit I

Cytochrome c oxidase subunit II.

Cytochrome c oxidase subunit III.

NADH dehydrogenase subunit 2

NADH-ubiquinone oxidoreductase chain 4

Glycetaldehyde 3-phosphate dehydrogenase

Transaldolase

Fructose-bisphosphate aldolase A

Glutamate carboxypeptidase-like protein 1.

Serine--pyruvate aminotransferase

$60 \mathrm{kD}$ a heat shock protein, mitochondrial

Heat shock protein HSP 90-alpha

GRB2-related adaptor protein 2

Transposase-like

ReO_6-like

Cytohesin binding protein $\mathrm{HE}$.

Coronin 1B

Profilin I.

Meprin A alpha-subunit

Immunoglobulin epsilon receptot alpha

Thymosin beta-4

Lysozyme C precursor
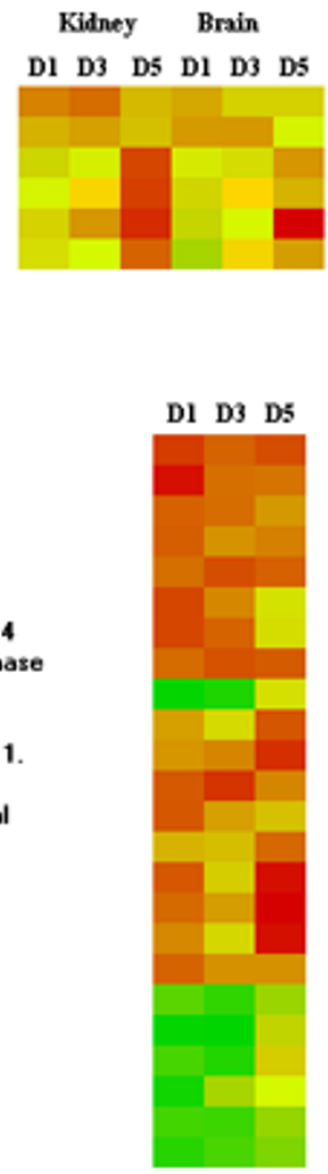

Brain

O.1
Aquaporin-CHIP
Myosin light chain 1. skeletal
Myosin regulatory light chain 2, cardiac
Myosin heavy chain, skeletal
Myosin heavy chain. cardiac
Troponin I, fast skeletal
Troponin T, fast skeletal
Iroponin C, skeletal
Tropomyosin alpha 3 chain
Actin, alpha skeletal
Parvalbumin alpha.
Sarcoplasmic reticulum calcium ATPase
Mictotubule-associated ptotein RP/EB
Creatine kinase. M chain
Glyceraldehyde 3-phosphate dehydrogenase
40S ribosomal protein S11.
40S ribosomal protein S9.
Putative pre-mRNA splicing factor RNA helicase
Spliceosomal U5 snRNP-specific 15 kDa protein

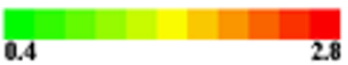

ATP-dependent CLP protease

NF-kappaB inhibitor alpha

Dnal homolog subfamily $\mathrm{C}$ member 5

Deltex homolog

14.3-3 C1

14-3-3 B1

14-3-3 C2

Transcription regulator protein BACH1

Stress-activated protein kinase-4

Macrophage receptor MARCO

Adenosine deaminase

PEST-containing nucleat protein.

Retinoic acid receptor responder protein

Aryl hydrocarbon receptor

GRB2-related adaptor protein

Protein phosphatase 2C

Zinc finger protein 148

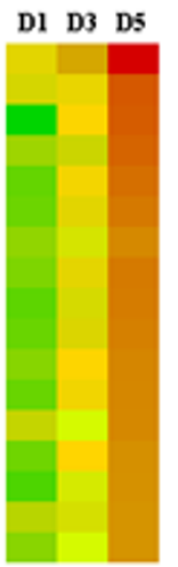

Figure 3

Examples of differentially expressed genes. Pooled RNA from 4 fish was hybridized in dye-swap experiments to two microarrays on which each gene was printed 6 times (total of 12 replicates). Differential expression was analysed with Student's t-test $(P<0.01)$; the expression ratio is coded with color scale.

with correlated expression profiles within the functional classes using results of 35 microarray experiments conducted by our laboratory. Both factorial and cluster analyses revealed 9 defense response genes that showed tightly coordinated expression being induced with stress. We continued search using the consensus profile of this subgroup and found 47 positively and 1 negatively correlated genes (Pearson $r>|0.65|$ ). Of these 29 were identified by the protein products (Figure 5A), 19 being from the set of selected clones. Expression of the stress-responsive genes changed significantly in several experiments including this study (Figure 5B). They were up-regulated in kidney with stress and injection of cortisol, combination of these treatments showed an additive effect (Figure 5C). These genes also responded to the model water contaminants, being induced with low and medium and repressed with high doses (Figure 5D).

\section{Discussion}

\section{Stress response in rainbow trout}

Our study aimed at comparison of time-course of stress response in rainbow trout brain and kidney and finding of 
Table 3: Enrichment of Gene Ontology categories in the lists of differentially expressed genes. Analysis with exact Fisher's test, ( $p<$ 0.05 ) was made using the composition of microarray as a reference. The numbers of differentially expressed genes and genes on the microarray are in parentheses.

\begin{tabular}{ll}
\hline Brain & Kidney \\
\hline Intracellular signaling cascade $(19 / 47)$ & Mitochondrion $(19 / 7 \mid)$ \\
RAS protein signal transduction $(6 / 9)$ & Electron transporters $(13 / 43)$ \\
GTPase mediated signal transduction $(11 / 16)$ & Extracellular $(19 / 70)$ \\
Chaperones $(16 / 40)$ & Endopeptidases $(8 / 22)$ \\
Heat shock proteins $(8 / / 6)$ & Metallopeptidases $(7 / / 2)$ \\
Metal ion binding $(31 / 80)$ & Zinc ion binding $(8 / 24)$ \\
Carriers $(15 / 37)$ & \\
Potential-driven transporters $(7 / 9)$ & \\
Calcium ion binding $(20 / 41)$ & \\
Magnesium ion binding $(8 / 14)$ & \\
Cytoskeleton $(27 / 76)$ & \\
Myofibril $(16 / 16)$ & \\
Microtubule-based process $(6 / 6)$ & \\
\hline
\end{tabular}

a diagnostic set of genes. These tasks were implemented with an aid of Gene Ontology annotation, which was used in several modes. The most straightforward and commonly used approach is counting of Gene Ontology classes in the lists of differentially expressed genes. Statistical inference of enrichment and depletion is made with Z-score of hypergeometric distribution, exact Fisher's test or its modifications. Such analyses helped us to interpret differences of stress responses in the brain and kidney (Table 3). In the brain handling stress mainly affected expression of transcripts for structural proteins (especially cytoskeleton), signal transduction, and binding of metal ions, whereas mitochondria, extracellular structures and peptidases appeared the key targets in the kidney. Computer-assisted analysis of Medline abstracts suggested that most of these themes have not been addressed in the studies of fish stress (Table 1).

Searches of the enriched Gene Ontology categories associated with differentially expressed transcripts is useful for rapid screens of microarray data; however, it presumes coordinated expression of functionally related genes. This assumption is not valid for many classes, especially large and heterogenous groups, such as stress and defense response. Because the gene composition of microarray is used as a reference, uneven presentation of functional categories can distort the results. Finally, this analysis does not take into account direction and magnitude of differential expression. To overcome these problems, enrichment of Gene Ontology classes is analysed in groups of genes with similar expression profiles revealed with cluster or factorial analyses. In this study we preferred straight comparison of Gene Ontology classes by the mean log expression ratios which helped in interpretation of the time-course of stress response.

In the kidney temporal alterations were relatively weak though significant. Expression of peptidases (especially collagenases) increased steadily, which implied possible degradation of tissue with prolonged stress. We could expect abrupt fluctuations in the rainbow trout brain, since transient induction and up-regulation of gene expression was observed in response to cold in the brain of channel catfish [4]. In our study most differentially expressed genes fell into two groups with distinct temporal profiles which showed remarkable coherence of the functional classes. Early phase was associated with dramatic up-regulation of structural and metal binding proteins, which were repressed in later phases. Expression of genes involved in stress and defense response, apoptosis and signal transduction, cell cycle and growth changed in a reciprocal fashion. Activation of metal binding proteins could be accounted for the role of ions (particularly calcium) in multiple pathways of gene expression regulation in the brain [26]. Motor proteins of cytoskeleton play key roles in the transport of vesicles and the establishment and rearrangement of neuronal networks [27-29] which also could be implicated to the stress response in fish. However, in mammals these functions are associated with non-muscle isoforms and therefore differential expression of the sarcomeric proteins was unexpected. Additional experiments confirmed induction of these proteins at early phase of stress response. Previously we observed high activity of skeletal $\alpha$-actin and myosin light chain 2 promoters in the neural tissues of rainbow trout embryos [30]. Sequencing of salmonid fish cDNA libraries pro- 


\section{Brain}

\begin{tabular}{|l|l|}
\hline & \\
\hline 0.3 & 12
\end{tabular}

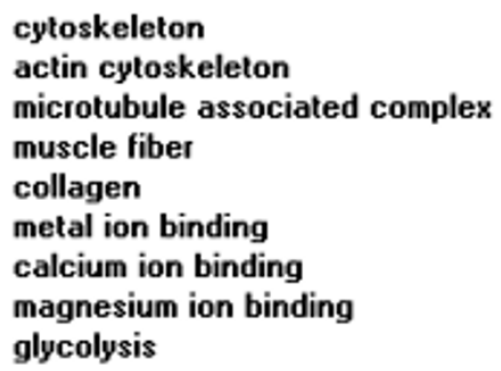

Kidney

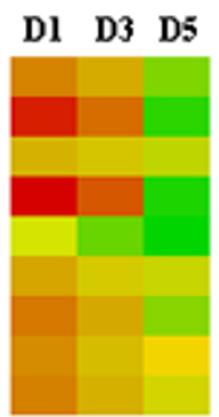

0.4
metal ion binding
transition metal ion binding
iron ion binding
oxidative phosphorylation
oxidoreductases
collagen
RNA binding
amine metabolism
carboxylic acid metabolism

D1 D3 D5

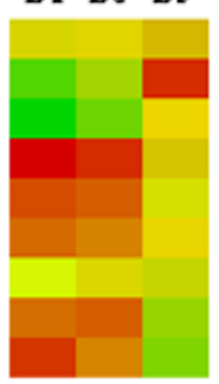

0.6

1.5

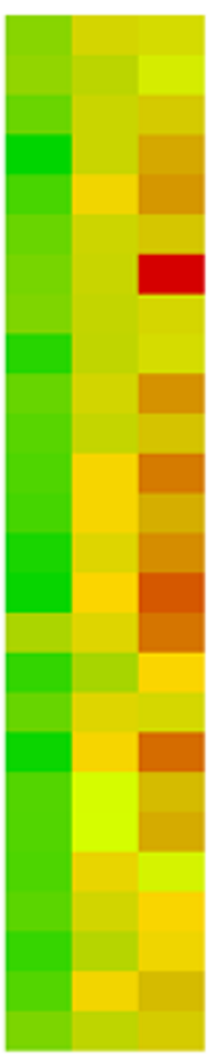

collagenases

metalloendopeptidases

metallopeptidases

endopeptidases

peptidases

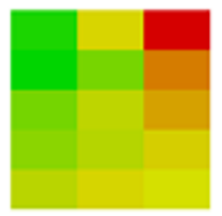

\section{Figure 4}

Time-course of stress response in the brain and kidney. Differentially expressed genes were grouped by the Gene Ontology categories and mean log (expression ratios) were analysed with Student's t-test. Panel presents examples of categories that showed significant difference between the time points $(p<0.05)$. The values are coded with color scale. 
A

\begin{tabular}{lll}
\hline 6.32 & 0.0 & 4.65
\end{tabular}

Mitogen-activated protein kinase $13-0.94$

Adenosine deaminase - 0.94

Aryl hydrocarbon receptor - 0.93

Heat shock $27 \mathrm{kDa}-0.89$

Siah2 protein -0.89

Transcription regulator protein BACH1 - 0.87

Macrophage receptor MARCO - 0.87

Coatomer epsilon subunit - $\mathbf{0 . 8 5}$

Myeloperoxidase - $\mathbf{0 . 8 3}$.

Hypoxia induced factor $-\mathbf{0 . 8 3}$

Glutathione reductase, mitochondrial -0.83

PEST-containing nuclear protein $-\mathbf{0 . 8 2}$

Peptide methionine sulfoxide reductase $\mathbf{- 0 . 8 1}$

Zinc finger protein $148-0.80$

GRB2-related adaptor protein $2-0.79$

Alpha-2,8-sialyltransferase - 0.79

CD39 antigen - 0.78

Fructose-bisphosphate aldolase A - 0.76

Rotamase - 0.74

SAC2 suppressor of actin mutations $-\mathbf{0 . 7 4}$

Nitric oxide synthase $2-0.74$

Catalase - 0.73

MAPK/ERK kinase kinase 5 - 0.72

C3a anaphylatoxin chemotactic receptor -0.71

Similar to RIKEN 2810018A15 - 0,69

Similar to RIKEN 4921505C17 - 0.69

Glucocorticoid receptor - $\mathbf{0 . 6 8}$

CD2 antigen - 0.65

Transferrin - [-0.65)
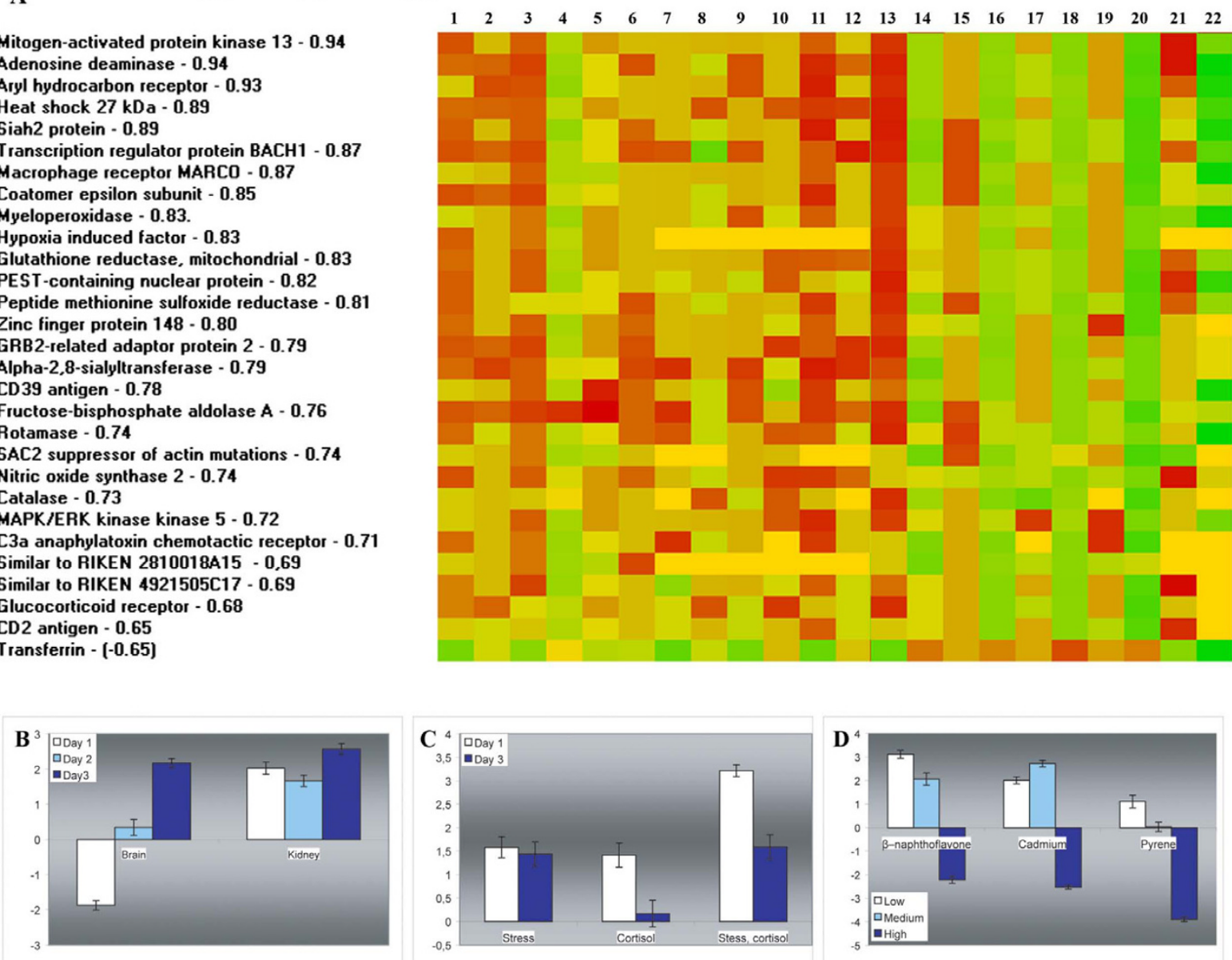

\section{Figure 5}

Expression of stress-responsive genes. A: Experiments. I-6: response to handling stress, this study. Kidney, I day (I), 3 days (2) and 5 days (3); brain, I day (4), 3 days (5) and 5 days (6). 7-I2: response to handling stress and exogenous cortisol in kidney. Cortisol, I day (7) and 3 days (8); stress, I day (9) and 3 days (10), combination of stress and injection of cortisol, I day (II) and 3 days (I2). I3-20: exposure of yolk sac fry to model contaminants [34]. $\beta$-naphthoflavone, low (I3) and high (I4) dose; cadmium, low (15) and high (16) dose; carbon tetrachloride, low (I7) and high (18) dose; pyrene, low (19) and high (20) dose. 2 I-22: response of yolk sac fry to transportation stress, rainbow trout (2I) and Atlantic salmon (22). Ranks are coded with color scale; correlation coefficients (Pearson $r$ ) with the mean expression profile are indicated. B-C: the mean ranks \pm SE of the stress-responsive genes in 3 experiments. A: this study; $\mathbf{B}$ - response to handling stress and injection of cortisol in kidney; $\mathbf{C}$ - exposure of yolk sac fry to $\beta$-naphthoflavone, cadmium and pyrene at low, medium and high doses.

vided evidence for the brain expression of sarcomeric proteins, but their role remains fully unknown. At present there is sparse evidence for differential expression of structural muscle proteins in the mammalian brain. For example regulation of troponin I with dextromethorphan (antagonist of excitatory amino acid receptors) was reported in the rat hyppocampus and cortex [31].
Grouping of individual differentially expressed genes by the functional classes reduced noise and enhanced cluster and factorial analyses. This helped to identify stressresponsive genes that showed correlated expression in 35 microarray experiments ( 22 experiments are shown in Figure 5A). Association with stress is well established for most of these proteins and some are used as stress mark- 
ers. The list of enriched Gene Ontology categories (stress, defense and humoral immune response, signal transduction and response to oxidative stress, $\mathrm{p}<0.05)$ suggested biological relevance of this group. Computer analysis of Medline abstracts (Table 1) showed that immunity and metabolism of reactive oxidative species are prioritized in studies of fish stress and these functional categories were enriched in the list of stress-responsive genes. Thus Gene Ontology provided a useful starting point for search of functionally related genes and results of these analyses can be used further for the revision of annotations.

\section{Construction of microarrays}

Results of our experiments helped to evaluate the strategy used in construction of the rainbow trout microarray. Researchers developing microarrays for new species are commonly choosing between specially selected genes and clones from normalized and subtracted cDNA libraries. We used SSH, which is at present probably the most popular method of subtraction. Though proven efficient in many studies, this method has a number of drawbacks. Subtraction requires re-association of tester and formation of double-stranded DNA, hence many rare transcripts are not cloned and variations in concentrations of cDNA and hybridization conditions may have strong impacts on library composition. High redundancy is a common feature of the SSH libraries. Apart from these problems, rapid alterations of gene expression observed in this study and many other microarray experiments make the advantages of subtractive cloning ambiguous. Subtraction achieves enrichment of the transcripts, which are over or under represented in the test sample. In many cases one sample will not provide coverage of differentially expressed genes for the whole series, whereas pooling of samples may reduce fluctuations. Furthermore, we observed relatively high ratio of differentially expressed genes among the clones from the unsubtracted cDNA libraries, which are easier for construction and much less redundant. The advantage of subtractive cloning becomes negligible when microarrays are used for different, though related research tasks (Fig. 1B).

At present selection of genes for microarrays is facilitated with advances of functional annotation. This helped us to improve presentation of many functional categories (Table 1) and enhanced interpretation of results. Most of the selected genes did not show differential expression in our studies, however $63 \%$ of stress-responsive genes were from this group. In our view, this finding is a strong argument for utilizing Gene Ontology in the development of specialized platforms.

Given the limited number of spots on slides, microarray design requires a careful balance between the number of genes and replication of spots. Apparent advantages of genome-wide platforms are compromised with the problems associated with identifying significantly differentially expressed genes. We preferred combination of multiple spotting and dye-swap normalization, which ensured robust normalization and accurate detection of differential expression at low ratios. Coordinated expression of functionally related genes suggested biological relevance of relatively small alterations in the transcription levels. Selection of differentially expressed genes by the cutoff values would result in loss of valuable information in our experiments. For instance, most of the stressresponsive genes showed small or moderate expression changes, the identification of this group would not be likely without multiple replications.

\section{Conclusions}

1. Combination of EST and selected genes appears a reasonable way for construction of cDNA microarrays. Multiple replications of spots and dye swap design of hybridization ensure robust normalization and high power of statistical analyses. Finding of differential expression at small ratios is essential for the functional interpretation of microarray data.

2. Stress response in fish brain and kidney is different both by the target functions and time-course. In brain slow progression of adaptive response was preceded with dramatic transient induction of motor and metal ion binding proteins. Prolonged stress was likely to result in slow degradation of extracellular matrix in kidney.

3. Finding of stress-responsive genes provides possibility for measurement of stress in various conditions and search for the functionally related genes.

\section{Methods}

\section{Computer-assisted analysis of Medline abstracts}

Search of Medline was made with queries: "fishes AND stress" (1060 abstracts) and "fishes NOT stress" (10069 abstracts). Abstracts were split into separate words and a list of non-redundant terms was composed. The numbers of abstracts including each term were estimated. The terms were ranked by the Z-scores of hypergeometric distribution and enrichment was analysed with exact Fisher's test $(\mathrm{p}<0.05)$.

\section{Experiments with fish, exposure and sampling}

One year old rainbow trout were stressed with netting for $2 \mathrm{~min}$, this treatment was repeated once a day for a duration of 5 days. Fish were killed with over-dose of anaesthetic (MS-222) and blood was taken from the caudal vein. The kidneys and brains were snap-frozen in liquid nitrogen. Plasma cortisol was determined with RIA using Orion Spectra Cortisol kit. 
Table 4: Primers used for qPCR.

\begin{tabular}{ll}
\hline Gene & Sequence \\
\hline GRB2-related adaptor protein 2 & Forward 5'-GCCAGAGCACCCCAGGAGAT-3' \\
Collagenase type IV & Reverse 5'-GGCTGAGAGGATGGGGCTGA-3' \\
Troponin T & Forward 5'-AACATCAGAAACGCCCTCAT-3' \\
40 S ribosomal protein SI2 & Reverse 5'-TGGTGGTAGTGGTAGTGGAC-3' \\
ESTI & Forward 5'-TGGGAAGAAGGAAACTGAGA-3' \\
& Reverse 5'-CTCTTACGCAGGGTTGTGAC-3' \\
EST2 & Forward 5'-AGACCGCACTCATCCACGAC-3' \\
& Reverse 5'-CCACTTTACGGGGTTTTCCT-3' \\
& Forward 5'-CGGAGAAGGAGAACCCACAG-3' \\
\hline
\end{tabular}

\section{Preparation of microarrays}

RNA was extracted with Trizol reagent (Invitrogen) and mRNA was purified with Dynabeads kit (Dynal). SSH cloning was performed as described [17]. For preparation of normalized libraries, synthesis of cDNA with PowerScript reverse transcriptase (Clontech) was primed with oligonucleotides including EcoRI and NotI sites: 5'ACGAGGCGAATTCACAGAGAGGAG(T)VN-3', 5'-GAGAGAGAGTGGTGCGGCCGCGGTGTATGGGG-3'). Doublestranded cDNA was generated using Advantage DNA polymerase mix (Clontech) and PCR primers: 5'-ACGAGGCGAATTCACAGAGAGGAG-3' and 5'-GAGAGTGGTGCGGCCGCGGTGTA-3'. The PCR products were purified with QIAquick kit (Qiagen), precipitated with ethanol and dissolved to $1 \mu \mathrm{g} / \mu \mathrm{l}$ in hybridization buffer $(1 \mathrm{M}$ $\mathrm{NaCl}, 50 \mathrm{mM}$ HEPES (pH 8.3), $1 \mathrm{mM}$ EDTA). DNA was denaturated for $5 \mathrm{~min}$ at $94^{\circ} \mathrm{C}$. Following re-association at $72^{\circ} \mathrm{C}$ for 16 hours, DNA was ethanol precipitated and digested with $150 \mathrm{U}$ of exonuclease III (MBI Fermentas) for $15 \mathrm{~min}$ at $37^{\circ} \mathrm{C}$. This treatment eliminates re-associated double-stranded DNA [19]. Single-stranded DNA was PCR amplified, size separated with agarose gel electrophoresis and cloned into pGEM ${ }^{\circledR}-11 \mathrm{Zf}(+)$ (Promega). Normalized and subtracted cDNA libraries were prepared from the stressed fish (whole fry, brain, kidney and spleen of 1-year old fish). A number of clones were from the rainbow trout and Baltic salmon cDNA libraries constructed in University of Turku. The sequences were analysed with stand-alone blastn and blastx [32] Microarray incldued 315 genes selected by the Gene Ontology functional categories. Of these, 282 clones were from the normalized multi-tissue library [20] and the rest were produced with RT PCR. The cDNA inserts were amplified with PCR using universal primers and purified with Millipore Montage PCR96 Cleanup Kit. DNA was spotted onto poly-(L) lysine-coated slides and each clone was printed in 6 replicates.

\section{Microarray analyses}

Total RNA was extracted with Trizol reagent (Invitrogen) and 4 individuals were pooled in each sample. Stressed fish was compared with time-matched control. Labeling with Cy3- and Cy5-dCTP (Amersham Pharmacia) was made using SuperScript III (Invitrogen) and oligo(dT) primer; cDNA was purified with Microcon YM30 (Millipore). We used a dye swap experimental design [14,15] and each sample was hybridized to two microarrays. For the first slide, test and control cDNA were labeled with $\mathrm{Cy} 5$ and Cy3 respectively, and for the second array dye assignments were reversed. The slides were pretreated with $1 \%$ BSA, fraction $\mathrm{V}, 5 \times \mathrm{SSC}, 0.1 \%$ SDS (30 min at $\left.50^{\circ} \mathrm{C}\right)$ and washed with $2 \times \operatorname{SSC}(3 \mathrm{~min})$ and $0.2 \times \operatorname{SSC}(3$ min) and hybridized overnight in cocktail containing 1.3 x Denhardt's, 3 x SSC $0.3 \%$ SDS, $0.67 \mu \mathrm{g} / \mu \mathrm{l}$ polyadenylate and $1.4 \mu \mathrm{g} / \mu \mathrm{l}$ yeast tRNA. All chemicals were from SigmaAldrich. Scanning was performed with ScanArray 5000 and images were processed with QuantArray (GSI Luminomics). The measurements in spots were filtered by criteria $I / B \geq 3$ and $(I-B) /\left(S_{I}+S_{B}\right) \geq 0.6$, where $I$ and $B$ are the mean signal and background intensities and $S_{I}, S_{B}$ are the standard deviations. After subtraction of mean background, lowess normalization [33] was performed. Differential expression was analysed with Student's t-test ( $\mathrm{p}<$ $0.01)$ and the genes were ranked by the $\log (\mathrm{p}$-level).

\section{Quantitative RT PCR}

Primers (Table 4) were designed to amplify 194-305 b fragments. RNA was processed with Rnase-free Dnase (Promega). Synthesis of cDNA with Superscript III reverse transcriptase (Invitrogen) was primed with oligo(dT). Analyses were carried out using Dynamo SYBR Green kit (Finnzymes) and ABI Prism 7700 (Amersham-Pharmacia). 


\section{Author's contributions}

AK designed microarray, carried out experiments with fish and data analyses and drafted the manuscript. HK conducted the microarray analyses. PP developed software for annotation of genes and analyses of Medline abstracts. CR constructed the multi-tissue cDNA library and provided the selected genes. SA developed software for management of microarray data and performed the statistical analyses. HM coordinated research. All authors read and approved the final manuscript.

\section{Acknowledgements}

This study was supported by the National Agency of Technology, Finland. We wish to thank Rolf Sara (CBT, University of Turku) for preparation of cDNA microarrays and Seppo Kukkonen for analyses of plasma cortisol.

\section{References}

I. Gracey AY, Troll JV, Somero GN: Hypoxia-induced gene expression profiling in the euryoxic fish Gillichthys mirabilis. Proc Natl Acad Sci U S A 200I, 98:1993-1998.

2. Rise ML, von Schalburg KR, Brown GD, Mawer MA, Devlin RH, Kuipers N, Busby M, Beetz-Sargent M, Alberto R, Gibbs AR, Hunt P, Shukin R, Zeznik JA, Nelson C, Jones SR, Smailus DE, Jones SJ, Schein JE, Marra MA, Butterfield YS, Stott JM, Ng SH, Davidson WS, Koop BF: Development and application of a salmonid EST database and cDNA microarray: data mining and interspecific hybridization characteristics. Genome Res 2004, 14:478-490.

3. Williams TD, Gensberg K, Minchin SD, Chipman JK: A DNA expression array to detect toxic stress response in European flounder (Platichthys flesus). Aquat Toxicol 2003, 65: I4I-I57.

4. Ju Z, Dunham RA, Liu Z: Differential gene expression in the brain of channel catfish (Ictalurus punctatus) in response to cold acclimation. Mol Genet Genomics 2002, 268:87-95.

5. Oleksiak MF, Churchill GA, Crawford DL: Variation in gene expression within and among natural populations. Nat Genet 2002, 32:261-266.

6. Ton C, Stamatiou D, Dzau VJ, Liew CC: Construction of a zebrafish cDNA microarray: gene expression profiling of the zebrafish during development. Biochem Biophys Res Commun 2002, 296: I|34-I|42

7. Ashburner M, Ball CA, Blake JA, Botstein D, Butler H, Cherry JM, Davis AP, Dolinski K, Dwight SS, Eppig JT, Harris MA, Hill DP, IsselTarver L, Kasarskis A, Lewis S, Matese JC, Richardson JE, Ringwald M, Rubin GM, Sherlock G: Gene ontology: tool for the unification of biology. The Gene Ontology Consortium. Nat Genet 2000, 25:25-29.

8. Doniger SW, Salomonis N, Dahlquist KD, Vranizan K, Lawlor SC, Conklin BR: MAPPFinder: using Gene Ontology and GenMAPP to create a global gene-expression profile from microarray data. Genome Biol 2003, 4:R7.

9. Draghici S, Khatri P, Martins RP, Ostermeier GC, Krawetz SA: Global functional profiling of gene expression. Genomics 2003, 8I:98-104.

10. Herrero J, Al-Shahrour F, Diaz-Uriarte R, Mateos A, Vaquerizas JM, Santoyo J, Dopazo J: GEPAS: A web-based resource for microarray gene expression data analysis. Nucleic Acids Res 2003, 31:346I-3467

II. Zeeberg BR, Feng W, Wang G, Wang MD, Fojo AT, Sunshine M, Narasimhan S, Kane DW, Reinhold WC, Lababidi S, Bussey KJ, Riss J, Barrett JC, Weinstein JN: GoMiner: a resource for biological interpretation of genomic and proteomic data. Genome Biol 2003, 4:R28

12. Robinson PN, Wollstein A, Bohme U, Beattie B: Ontologizing gene-expression microarray data: characterizing clusters with Gene Ontology. Bioinformatics 2004, 20:979-98I.

13. McCarroll SA, Murphy CT, Zou S, Pletcher SD, Chin CS, Jan YN, Kenyon $\mathrm{C}$, Bargmann $\mathrm{Cl}$, $\mathrm{Li} \mathrm{H}$ : Comparing genomic expression patterns across species identifies shared transcriptional profile in aging. Nat Genet 2004, 36:197-204.

14. Kerr MK, Churchill GA: Statistical design and the analysis of gene expression microarray data. Genet Res 2001, 77:123-128.
15. Yang YH, Dudoit S, Luu P, Speed T: Normalization for cDNA Microarray Data. In In Microarray Optical Technologies and Informatics Edited by: Bittner ML, Chen Y, Dorsel AN, Dougherty ER. San Jose: SPIE, Society for Optical Engineering; $200 \mathrm{I}$.

16. Wendelaar Bonga SE: The stress response in fish. Physiol Rev 1997, 77:591-625.

17. Diatchenko L, Chenchik A, Siebert P: Suppression subtractive hybridization: A method for generating subtracted CDNA libraries starting from poly (A+) or total RNA. In In RT-PCR Methods for Gene Cloning and Analysis Edited by: Siebert P, Larrick J. BioTechniques Books; 1998:213-239.

18. Chenchik A, Zhu Y, Diatchenko L, Li R, Hill J, Siebert P: Generation and use of high quality cDNA from small amounts of total RNA by SMART PCR. In In RT-PCR Methods for Gene Cloning and Analysis Edited by: Siebert P, Larrick J. BioTechniques Books; 1998:305-319.

19. Zeng J, Gorski RA, Hamer D: Differential cDNA cloning by enzymatic degrading subtraction (EDS). Nucleic Acids Res 1994, 22:438I-4385.

20. Rexroad CE 3rd, Keele JW, Gahr SA, Palti Y, Lee Y, Karamycheva S, Quackenbush J: Sequence analysis of a rainbow trout cDNA library and creation of a Gene Index. Cytogenetics and Genome Research 2003, 102:347-354.

21. Barton BA, Iwama GK: Physiological changes in fish from stress in aquaculture with emphasis on the response and effects of corticosteroids. Annual Review of Fish Diseases 1991, I:3-26.

22. Nichols NR: Ndrg2, a novel gene regulated by adrenal steroids and antidepressants, is highly expressed in astrocytes. Ann $N$ Y Acad Sci 2003, 1007:349-356.

23. Boulkroun S, Fay M, Zennaro MC, Escoubet B, Jaisser F, Blot-Chabaud $\mathrm{M}$, Farman $\mathrm{N}$, Courtois-Coutry $\mathrm{N}$ : Characterization of rat NDRG2 ( $\mathrm{N}$-Myc downstream regulated gene 2), a novel early mineralocorticoid-specific induced gene. J Biol Chem 2002, 277:3I506-3I5I5.

24. Halestrap AP, Brennerb C: The adenine nucleotide translocase: a central component of the mitochondrial permeability transition pore and key player in cell death. Curr Med Chem 2003, 10:1507-1525.

25. Amiry-Moghaddam M, Ottersen OP: The molecular basis of water transport in the brain. Nat Rev Neurosci 2003, 4:99I-I00I.

26. West AE, Chen WG, Dalva MB, Dolmetsch RE, Kornhauser JM, Shaywitz AJ, Takasu MA, Tao X, Greenberg ME: Calcium regulation of neuronal gene expression. Proc Natl Acad Sci U S A 200I, 98: | | 1024-II03I.

27. Brown J, Bridgman PC: Role of myosin II in axon outgrowth. Histochem Cytochem 2003, 5 I:42 I-428.

28. Bridgman PC: Myosin-dependent transport in neurons. J Neurobiol 2004, 58: 164-174.

29. Brown ME, Bridgman PC: Myosin function in nervous and sensory systems. J Neurobiol 2004, 58: I I8-I 30.

30. Krasnov A, Teerijoki H, Gorodilov Y, Mölsa H: Cloning of rainbow trout (Oncorhynchus mykiss) alpha-actin, myosin regulatory light chain genes and the 5'-flanking region of alpha-tropomyosin. Functional assessment of promoters. J Exp Biol 2003, 206:60I-608.

3I. Lee KH, Ahn Jl, Yu DH, Koh HC, Kim SH, Yang BH, Lee YS, Lee YS: Dextromethorphan alters gene expression in rat brain hippocampus and cortex. Int J Mol Med 2003, I I:559-568.

32. Altschul SF, Madden TL, Schaffer AA, Zhang J, Zhang Z, Miller W, Lipman DJ: Gapped BLAST and PSI-BLAST: a new generation of protein database search programs. Nucleic Acids Res 1997, 25:3389-3402.

33. Cleveland WS, Grosse E, Shyu WM: Local regression models. In In Statistical Models in S Edited by: Chambers JM, Hastie TJ. Pacific Grove: Wadsworth \& Brooks/Cole; 1992:309-376.

34. Koskinen H, Pehkonen P, Vehniäinen E, Krasnov A, Rexroad C, Afanasyev $\mathrm{S}$, Mölsa $\mathrm{H}$, Oikari A: Response of rainbow trout transcriptome to model chemical contaminants. Biochem Biophys Res Communs 2004, 320:745-753. 